\title{
Folate status of the population in the Canadian Health Measures Survey
}

\author{
Cynthia K. Colapinto MSc, Deborah L. O'Connor PhD, Mark S. Tremblay PhD
}

Competing interests: None declared.

This article has been peer reviewed.

\section{Correspondence to:} Dr. Mark Tremblay; mtremblay@cheo.on.ca

CMAJ 2011. DOI:10.1503 /cmaj.100568

\begin{abstract}
Background: Low folate concentrations are inversely associated with birth defects, including neural tube defects, congenital heart disease and oral clefts. Conversely, high folate concentrations may be associated with adverse outcomes, including increased risk of colorectal cancer among those with pre-existing neoplasms. The purpose of our study was to investigate the folate status of a nationally representative sample of Canadians, including a subset of women of childbearing age.
\end{abstract}

Methods: We examined red blood cell folate concentrations among members of the general population aged $6-79$ years $(n=5248)$ and separately among women of childbearing age (15-45 yr, $n=1162)$, as recorded by the Canadian Health Measures Survey and measured by immunologic assay. We assessed the data for significant differences by age, sex and socioeconomic status.

Results: Less than $1 \%$ of Canadians showed folate deficiency (red blood cell folate $<305 \mathrm{nmol} / \mathrm{L}$ ) and 40\% showed high folate con-

$\mathrm{F}$ olic acid represents both a public health success and a controversial debate over associated health risks. Fortification with folic acid of Canadian white wheat flour $(150 \mu \mathrm{g} / 100 \mathrm{~g})$ and other selected grains in 1998 has been linked to a $46 \%$ reduction in the prevalence of neural tube defects. ${ }^{1}$ Declines in rates of neural tube defects have also been documented in the United States and Chile after fortification of grains with folic acid. ${ }^{23}$ To further reduce the risk of folate-dependent neural tube defects, women of childbearing age are encouraged to eat folate-rich foods and take a multivitamin supplement containing folic acid $(0.4 \mathrm{mg} / \mathrm{d}) .{ }^{4}$ Higher-dose supplements $(4-5 \mathrm{mg} / \mathrm{d})$ are recommended for women at increased risk of giving birth to a baby with a neural tube defect (e.g., those who regularly use folic acid antagonist medications or have a family history of neural tube defects). ${ }^{5}$ Although biochemical assessment of the folate status of select subgroups of Canadians has been done, it has not been studied on a nationally representative sample centrations (> $1360 \mathrm{nmol} / \mathrm{L})$. Among women of childbearing age, $22 \%$ showed concentrations below those considered optimal for maximal neural tube defect-risk reduction $(<906 \mathrm{nmol} / \mathrm{L})$. Significant differences by age and socio-economic status, but not sex, were evident in median red blood cell folate concentrations, although concentrations in all groups exceeded recommended levels. No differences by age or income were found among women of childbearing age.

Interpretation: Folate deficiency is virtually nonexistent in the Canadian population, although high folate concentrations are evident. Additional research is needed to better understand the determinants of red blood cell folate among women of childbearing age who have concentrations below levels that are maximally protective against neural tube defects. Ongoing monitoring of the folate status of Canadians and the relationship between red blood cell folate and health outcomes is warranted. in over 30 years. $^{6-9}$ The recent Canadian Health Measures Survey provides data to fill this gap. The purpose of our study was to describe the current folate status of Canadians, including a subgroup of Canadian women of childbearing age, and to assess whether folate concentrations vary by age, sex and socio-economic status.

\section{Methods}

\section{Sources of data}

We used data from the 2007-2009 Canadian Health Measures Survey (Cycle 1), conducted by Statistics Canada in partnership with Health Canada and the Public Health Agency of Canada. The survey methodology is described briefly here and in greater detail elsewhere. ${ }^{7,10}$

\section{Canadian Health Measures Survey sampling}

The Canadian Health Measures Survey used a complex, multistage, cluster-sampling protocol 
to achieve a nationally representative crosssectional sample. The final sample is representative of approximately $96.3 \%$ of the Canadian population, and included 5604 Canadians aged 6 to 79 years balanced by sex in each of the following age groups: $6-11,12-19,20-39,40-59$ and 60-79 years.

\section{Survey methods}

Data were collected between March 2007 and February 2009. A Statistics Canada interviewer administered a detailed in-home health questionnaire, which included items about sociodemographic characteristics. One day to six weeks later, blood samples were taken by a certified phlebotomist in a mobile examination centre to measure a variety of analytes, including red blood cell folate..$^{10}$ Of the 8772 dwellings selected, $69.6 \%$ agreed to participate; $88.3 \%$ participated in the household survey and, of those, $84.9 \%$ attended the mobile clinic. The overall response rate was $51.7 \%$. Implied consent was obtained by household and a comprehensive consent process was employed in the clinic.

Ethics approval for the Canadian Health Measures Survey was obtained from the Health Canada Research Ethics Board and for this secondary data analysis from the Children's Hospital of Eastern Ontario and University of Ottawa Research Ethics Boards.

\section{Blood sampling}

Blood was taken from 5373 participants in the Canadian Health Measures Survey, with 5248 providing a usable sample for red blood cell folate measurement. Participants who refused to participate in the blood draw or did not have a usable sample were excluded $(n=356)$.

\section{Red blood cell folate concentration}

Red blood cell folate allows for an estimate of tissue folate stores. Venipuncture samples were collected in EDTA-treated vacutainers, then immediately processed on-site. After hematocrit measurement, aliquots of whole blood were frozen, stored at $-20^{\circ} \mathrm{C}$ and shipped on dry ice weekly to the Health Canada Nutrition Laboratory. ${ }^{10}$ Samples were thawed, diluted (1-in-26) with $0.5 \%$ ascorbic acid solution, allowed to incubate $\left(180^{\circ} \mathrm{C}\right)$ at room temperature and then analyzed for folate using the Immulite 2000 immunoassay (Siemens Canada Ltd.). ${ }^{11}$ Red blood cell folate concentration was calculated from the measured whole-blood folate concentration adjusting for red blood cell volume, without correction for plasma folate concentration. Accuracy and reproducibility of these procedures were assessed using the manufacturers' serum controls
(Con6: Trilevel multiconstituent control) and whole blood controls (BioRad Lyphochek Trilevel, Biorad Laboratories). Serum controls had an interassay coefficient of variation of less than 5\%, and all analyzed controls (serum, whole blood) were within $10 \%$ of target values.

Deficient folate status was defined as a red blood cell folate concentration of less than $305 \mathrm{nmol} / \mathrm{L}(<135 \mathrm{ng} / \mathrm{mL})$, a cut-off defined by the Institute of Medicine based on several studies reporting the appearance of hypersegmented neutrophils, a characteristic of megaloblastic anemia, at red blood cell folate concentrations below this level. ${ }^{12}$

The cut-off for folate status considered optimal for minimizing the risk of neural tube defects among women of childbearing age was set at $906 \mathrm{nmol} / \mathrm{L}$ or greater $(\geq 400 \mathrm{ng} / \mathrm{mL})$ and has been adopted by experts in the field. ${ }^{13,14}$

The concentration of red blood cell folate at which adverse effects occur in association with high intakes of folic acid is unknown, and no universally accepted cut-off is available. Leading researchers in the area have used distribution cut-offs from the National Health and Nutrition Examination Survey data in the United States to establish a high serum folate cut-off, but this has not been done for red blood cell folate ${ }^{15-17}$ Given that recent national Canadian data are unavailable, a similar but more conservative approach was taken to establish a cut-off for high red blood cell folate concentration from the most recent postfortification national American data. Therefore, a red blood cell folate concentration of greater than $1360 \mathrm{nmol} / \mathrm{L}$ (> $600 \mathrm{ng} / \mathrm{mL}$ ), which reflects the 97 th percentile from the National Health and Nutrition Examination Survey (1999-2004), was chosen as a cut-off for high red blood cell folate. ${ }^{15}$

\section{Selected socio-demographic factors}

The age groups of the Canadian Health Measures Survey sample were used for analyses, and a variable for women of childbearing age (15-45 years) was created. Socio-economic status was examined by per-person household income equivalents (which grouped respondents into quartiles after adjusting for family size and composition) and by highest level of household education (less than secondary, secondary graduation, some postsecondary, postsecondary graduation). ${ }^{18}$

\section{Statistical analysis}

Descriptive statistics (frequencies, medians, percentiles) were used to describe the population and estimate red blood cell folate concentrations by age, sex and socio-economic status. Red blood cell folate in the general population was 
assessed for deficiency and high concentrations, whereas women of childbearing age were examined for concentrations below those considered optimal for minimizing the risk of neural tube defects. ${ }^{12,13}$ Differences between sex and age groups by education level and income quartile were examined using $t$ tests. All estimates were based on weighted data to represent the Canadian population. Variance estimation (95\% confidence intervals) and significance testing ( $t$ test) were based on the bootstrap technique to account for the complex sampling design. ${ }^{19}$ Significance was defined as a $p$ value of $<0.05$ and a Bonferroni adjustment was applied in cases of multiple comparisons.

\section{Results}

A demographic description of the population by age, sex, income and education can be found in
Table 1. Overall, almost $100 \%$ of Canadians met or exceeded the cut-off level in the general population for deficiency of red blood cell folate concentration $(<305 \mathrm{nmol} / \mathrm{L})$. High red blood cell folate concentrations were found in $40 \%$ (> $1360 \mathrm{nmol} / \mathrm{L}$ ) of the general population. Among women of childbearing age, 22\% were below the cut-off level for concentration of red blood cell folate considered optimal for minimizing the risk of neural tube defects (<906 nmol/L).

Median red blood cell folate concentrations were highest among participants aged 60 to 79 years (1409 nmol/L) and lowest among participants aged 12 to 19 years $(1120 \mathrm{nmol} / \mathrm{L})$ (Table 2). No significant difference in median red blood cell folate concentration between sexes was found. Elevated red blood cell folate concentrations across each percentile were evident, with the 5th percentile consistently above the cut-off level for fo-

\begin{tabular}{|c|c|c|c|c|c|c|c|c|}
\hline \multirow[b]{2}{*}{ Characteristic } & \multicolumn{4}{|c|}{ General population } & \multicolumn{4}{|c|}{ Women of childbearing age (15-45 yr) } \\
\hline & $\begin{array}{l}\text { Sample } \\
\text { size }\end{array}$ & $\begin{array}{l}\text { Weighted } \\
\text { sample size }\end{array}$ & $\%$ & $95 \% \mathrm{Cl}$ & $\begin{array}{l}\text { Sample } \\
\text { size }\end{array}$ & $\begin{array}{l}\text { Weighted } \\
\text { sample size }\end{array}$ & $\%$ & $95 \% \mathrm{Cl}$ \\
\hline \multicolumn{9}{|l|}{ Sex } \\
\hline Female & 2705 & 13910435 & 49.8 & $49.5-50.0$ & 1162 & 6676456 & 100.0 & - \\
\hline Male & 2543 & 14025760 & 50.2 & $50.1-50.5$ & - & - & - & - \\
\hline \multicolumn{9}{|l|}{ Age at time of clinic, yr } \\
\hline $6-11$ & 911 & 1830773 & 6.6 & $6.2-6.9$ & - & - & - & - \\
\hline $12-19$ & 945 & 3109972 & 11.1 & $10.8-11.5$ & 290 & 1058456 & 15.9 & $17.5-14.3$ \\
\hline $20-39$ & 1150 & 8748999 & 31.3 & $30.9-31.7$ & 643 & 4300645 & 64.4 & $67.3-61.4$ \\
\hline $40-59$ & 1202 & 9545984 & 34.2 & $33.7-34.6$ & 229 & 1317355 & 19.7 & $22.8-17.0$ \\
\hline $60-79$ & 1040 & 4700466 & 16.8 & $16.4-17.2$ & - & - & - & - \\
\hline \multicolumn{9}{|c|}{$\begin{array}{l}\text { Highest level of household } \\
\text { education }\end{array}$} \\
\hline Less than secondary & 327 & 1537019 & 5.5 & $4.1-7.4$ & 49 & 234820 & $<7.6+$ & $1.6-7.6$ \\
\hline Secondary graduation & 550 & 3576116 & 15.8 & $12.6-19.5$ & 105 & 634890 & 9.5 & $6.1-14.6 \neq$ \\
\hline Some postsecondary & 334 & 1805058 & 6.5 & $4.7-8.5$ & 78 & 503874 & 7.6 & $4.8-11.6$ \\
\hline Postsecondary graduation & 3900 & 20407347 & 73.0 & $66.3-78.9$ & 906 & 5151621 & 77.2 & $67.4-84.7$ \\
\hline Data unavailable & 137 & 1010655 & 3.6 & $2.7-4.8$ & 24 & 151251 & 2.3 & $1.5-3.5 \ddagger$ \\
\hline \multicolumn{9}{|c|}{$\begin{array}{l}\text { Income quartile (lowest to } \\
\text { highest) }\end{array}$} \\
\hline Q1 $(<\$ 25000)$ & 1368 & 6434838 & 23.0 & $20.6-26.4$ & 322 & 1863287 & 27.9 & $21.2-35.8$ \\
\hline Q2 (\$25 000 to $\$ 39999)$ & 1242 & 6523556 & 23.4 & $20.6-26.4$ & 251 & 1437931 & 21.5 & $17.3-26.4$ \\
\hline Q3 (\$40 000 to $\$ 59999)$ & 1196 & 6543379 & 23.4 & $20.0-27.3$ & 272 & 1548858 & 23.2 & $18.9-28.2$ \\
\hline $\mathrm{Q} 4(\geq \$ 60000)$ & 1110 & 6546371 & 23.4 & $19.8-27.6$ & 215 & 1230297 & 18.4 & $15.4-21.9$ \\
\hline Data unavailable & 332 & 1888050 & 6.8 & $5.8-7.8$ & 102 & 596082 & 8.9 & $6.5-12.2$ \\
\hline \multicolumn{9}{|c|}{$\begin{array}{l}\text { Note: } \mathrm{Cl}=\text { confidence interval. } \\
\text { *Comprises participants with a measured value of red blood cell folate concentration }(n=5248 \text {, data unavailable } n=356) \text {. } \\
\text { †Estimate was not provided because of extreme sampling variability or small sample size. If the coefficient of variation of the estimate was greater than } 33 \% \text {, the } \\
\text { estimate is indicated as being less than the upper limit of } 95 \% \mathrm{Cl} \text {. } \\
\text { †Data should be interpreted with caution because of high sampling variability (coefficient of variation } \geq 16.6 \text { and < } 33.3 \text { ). }\end{array}$} \\
\hline
\end{tabular}


late deficiency. Cumulative percent distributions for females and males by age are shown separately in Figure 1.

Significant differences in median red blood cell folate concentrations by income and education were few and inconsistent across age and sex groups (Appendix 1, available at www.cmaj.ca /cgi/content/full/cmaj.100568/DC1). No consistent differences in median red blood cell folate values by age and socio-economic status were evident among women of childbearing age.

\section{Interpretation}

Our study used the recently released Canadian Health Measures Survey data set to examine the folate status of the Canadian population. Folate deficiency was extremely low in the general population, though high concentrations of red blood cell folate were common. More than 20\% of Canadian women of childbearing age had a red blood cell folate concentration below that considered optimal for maximal reduction of risk of neural tube defects. ${ }^{13}$ Differences by age and socio-economic status were seen in the general population but not among women of childbearing age.

Given that comparable national-level Canadian data are unavailable, the Canadian Health Measures Survey was modelled after the National Health and Nutrition Examination Survey. The United States also fortifies grain products with folic acid, making the American survey an appropriate comparator. ${ }^{20}$ In the period of 2005 to 2006 (postfortification), the prevalence of folate deficiency in the American population was similar to that reported herein. Findings from postfortification studies of subgroups of Canadians show comparable results related to deficiency, and increases in circulating folate concentrations. For example, low rates of postfortification deficiency $(<1 \%)$ were found in a retrospective, population-based study involving Ontarian women of childbearing age, with the prefortification geometric mean for red blood cell folate increasing postfortification (527 to $741 \mathrm{nmol} / \mathrm{L}){ }^{8}$ In a sample of Newfoundlanders aged 65 years or older, deficiency was less than $1.6 \%$ with a pre- to postfortification increase in red blood cells of 625 to $818 \mathrm{nmol} / \mathrm{L} .{ }^{9}$ In a 2008 Ontario review of laboratory databases, $40 \%$ of women of childbearing age were not achieving a red blood cell folate concentration of $906 \mathrm{nmol} / \mathrm{L}$ or greater. ${ }^{21}$ Further, a recent randomized controlled trial in Toronto involving pregnant women, most of whom were consuming prenatal supplements containing folic acid $(1 \mathrm{mg} / \mathrm{d})$, showed a baseline geometric mean red blood cell folate in three groups that ranged from 2453 to $3635 \mathrm{nmol} / \mathrm{L} .{ }^{22}$

Some medical practitioners argue that many women of childbearing age need high-dose folic acid supplements and that doubling the level of folic acid fortification in the food supply should be considered. ${ }^{23,24}$ This argument has sparked considerable debate because folic acid fortification targets women of childbearing age by exposing the entire population to higher levels of folic acid. Given the absence of folate defi-

Table 2: Selected population percentile values for red blood cell folate concentrations ( $\mathrm{nmol} / \mathrm{L}$ ) by sex and age group

\begin{tabular}{|c|c|c|c|c|c|}
\hline \multirow[b]{2}{*}{ Sex } & \multirow[b]{2}{*}{ Age group, yr } & \multicolumn{4}{|c|}{ Percentile $(95 \% \mathrm{Cl})$} \\
\hline & & 5 th & 50th & 75th & 97th \\
\hline All & All & 621 (544-699) & 1248 (1164-1332) & 1619 (1501-1737) & $2580(2363-2797)$ \\
\hline Male & All & 618 (549-687) & $1233(1138-1327)$ & 1566 (1446-1687) & $2410(2196-2624)$ \\
\hline Female & All & $622(526-720)$ & 1261 (1164-1357) & 1664 (1543-1784) & 2715 (2493-2937) \\
\hline All & $6-11$ & 667 (546-788) & $1212(1132-1292)$ & $1491(1432-1550)$ & $1984(1859-2108)$ \\
\hline All & $12-19$ & $592(547-637)$ & 1120 (1037-1203) & 1377 (1266-1488) & 1977 (1843-2112) \\
\hline All & 20-39 & 629 (498-759) & $1190(1112-1268)$ & $1480(1380-1581)$ & 2269 (2066-2472) \\
\hline All & $40-59$ & $620(565-676)$ & 1292 (1167-1416) & 1697 (1546-1848) & 2676 (2473-2880) \\
\hline All & $60-79$ & 634 (481-787) & 1409 (1260-1558) & 1891 (1745-2037) & 2887 (2678-3097) \\
\hline Female* & $15-45$ & 615 (506-724) & $1193(1104-1282)$ & 1549 (1399-1700) & 2299 (2021-2577) \\
\hline Female* & $15-19$ & 606 (515-697) & 1173 (1054-1293) & 1470 (1313-1627) & 1978 (1789-2169) \\
\hline Female* & 20-39 & $600(443-758)$ & 1176 (1085-1266) & 1547 (1365-1730) & 2318 (2009-2627) \\
\hline Female* & $40-45$ & $620(498-741)$ & $1247(1056-1438)$ & 1652 (1428-1877) & 2605 (1987-3223) \\
\hline
\end{tabular}


ciency in the general population and the apparent shift toward Canadians having high serum folate concentrations, there appears to be little rationale for doubling levels of folic acid fortification in the Canadian food supply. Correction of folate deficiency and improved folate status, in part through fortification, has been associated with positive health outcomes such as the dramatic reduction in neural tube defects. ${ }^{1}$ However, given speculations about the possible

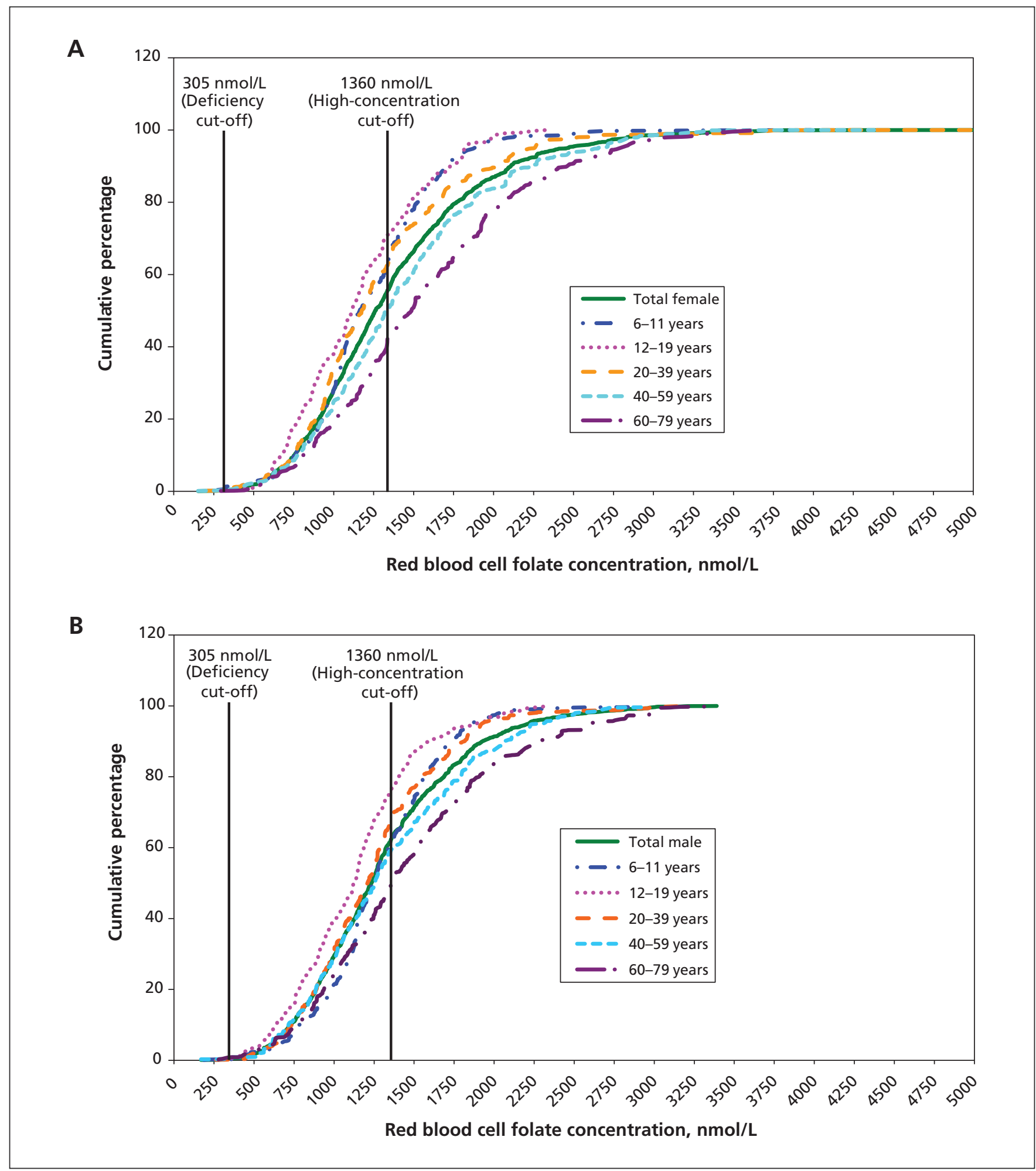

Figure 1: Cumulative percentile distributions of red blood cell folate concentrations by age group among female (A) and male (B) participants in the Canadian Health Measures Survey, 2007-2009. Folate concentrations for deficiency (305 nmol/L) and high folate concentrations (1360 $\mathrm{nmol} / \mathrm{L})$ are indicated by vertical lines. 
adverse effects associated with high levels of folic acid, including increased risk of certain cancers among those with pre-existing neoplasms, further attempts to improve the folate status of Canadian women of childbearing age by increasing fortification levels should be approached cautiously. ${ }^{25-28}$

\section{Strengths and limitations}

The main strengths of our study include a large, nationally representative sample and directly measured biomarkers. This research is limited by its inability to establish causation because of the cross-sectional nature of the Canadian Health Measures Survey. Further, although red blood cell folate is defined by the Institute of Medicine as the primary biochemical index to establish dietary reference intakes, there are significant interlaboratory differences in values obtained for red blood cell folate. ${ }^{12,29}$ As such, study-to-study comparisons need to be performed with caution. Although the cut-offs used in our study are undoubtedly assay-dependent, it is standard practice to use the same cut-off values regardless of the method used to measure of red blood cell folate concentration. For example, the US Centres for Disease Control and Prevention reported that at least one competitive binding assay resulted in red blood cell folate concentrations that were about $30 \%$ lower than either microbiological or liquid chromatography-tandem mass spectrometry. ${ }^{30}$ Interestingly, it was with the microbiological assay that the cut-off considered optimal for maximal reduction of risk of neural tube defects was established. To minimize the aforementioned limitation, strict quality control procedures were employed in our investigation to ensure both accuracy and precision of the red blood cell folate measurements.

\section{Conclusion}

Folate deficiency is virtually nonexistent in the Canadian population, regardless of income or education, and high folate concentrations are evident. Many women of childbearing age are still not achieving the concentrations considered optimal for maximal reduction of risk of neural tube defects. Although food insecurity has been identified previously as a risk factor for low folate intake, ${ }^{31}$ the median red blood cell folate concentration among women of childbearing age did not differ by income or education in our study.

Investigations into the determinants of suboptimal folate status are needed to develop intervention strategies to further mitigate neural tube defects. Given the high red blood cell folate con- centrations reported herein and speculation that exposure to high concentrations may have undesirable consequences for some, ongoing monitoring of the folate status of Canadians and study of the relation between red blood cell folate and health outcomes is warranted.

\section{References}

1. De Wals P, Tairou F, Van Allen MI, et al. Spina bifida before and after folic acid fortification in Canada. Birth Defects Res A Clin Mol Teratol 2008;82:622-6.

2. Bentley TG, Weinstein MC, Willett WC, et al. A cost-effectiveness analysis of folic acid fortification policy in the United States. Public Health Nutr 2009;12:455-67.

3. Llanos A, Hertrampf E, Cortes F, et al. Cost-effectiveness of a folic acid fortification program in Chile. Health Policy 2007;83: 295-303.

4. Prenatal nutrition. Ottawa (ON): Health Canada; 2009. Available: www.hc-sc.gc.ca/fn-an/nutrition/prenatal/index-eng.php (accessed 2010 Mar. 31)

5. High dose folic acid supplementation - questions and answers for health professionals. Ottawa (ON): Health Canada; 2010. Available: www.hc-sc.gc.ca/fn-an/nutrition/prenatal/fol-qa-qr-eng .php\#a2 (accessed 2010 Mar. 30).

6. Nutrition Canada national survey. 1970-1972. Toronto (ON): University of Toronto Data Library Service; 2005. Available: http:// datalib.chass.utoronto.ca/codebooks/utm/nutr70.htm (accessed 2010 Nov. 24).

7. Tremblay M, Wolfson M, Gorber SC. Canadian Health Measures Survey: rationale, background and overview. Health Rep 2007;18(Suppl):7-20.

8. Ray JG, Vermeulen MJ, Boss SC, et al. Increased red cell folate concentrations in women of reproductive age after Canadian folic acid food fortification. Epidemiology 2002;13:238-40.

9. Liu S, West R, Randell E, et al. A comprehensive evaluation of food fortification with folic acid for the primary prevention of neural tube defects. BMC Pregnancy Childbirth 2004;4:20.

10. Bryan S, St-Denis M, Wojtas D. Canadian Health Measures Survey: clinic operations and logistics. Health Rep 2007;18(Suppl): 53-70

11. Immulite 2000 folic acid insert. Mississauga (ON): Siemans Canada, Ltd.; 2009.

12. Institute of Medicine. DRI dietary reference intakes for thiamin, riboflavin, niacin, vitamin B6, folate, vitamin B12, pantothenic acid, biotin, and choline. Washington (DC): National Academy Press; 1998.

13. Daly LE, Kirke PN, Molloy A, et al. Folate levels and neural tube defects. Implications for prevention. JAMA 1995;274: 1698-702.

14. Tam C, McKenna K, Goh YI, et al. Periconceptional folic acid supplementation: a new indication for therapeutic drug monitoring. Ther Drug Monit 2009;31:319-26.

15. Pfeiffer CM, Johnson CL, Jain RB, et al. Trends in blood folate and vitamin B-12 concentrations in the United States, 1998 to 2004. Am J Clin Nutr 2007;86:718-27.

16. Selhub J, Morris MS, Jacques PF, et al. Folate-vitamin B-12 interaction in relation to cognitive impairment, anemia, and biochemical indicators of vitamin B-12 deficiency. Am J Clin Nutr 2009;89:702S-6S

17. Dietrich M, Brown CJ, Block G. The effect of folate fortification of cereal-grain products on blood folate status, dietary folate intake, and dietary folate sources among adult nonsupplement users in the United States. J Am Coll Nutr 2005;24:266-74.

18. Income trends in Canada: 1980-2003. Ottawa (ON): Statistics Canada; 2008. Cat no 13F0022XIE. Available: www.statcan.gc.ca /pub/13f0022x/00003/notedef/5801170-eng.htm\#famsize (accessed 2010 Mar. 29)

19. Rust KF, Rao JN. Variance estimation for complex surveys using replication techniques. Stat Methods Med Res 1996;5:283-310.

20. National Health and Nutrition Examination Survey. Atlanta (GA): Centers for Disease Control and Prevention; 2010. Available: www.cdc.gov/nchs/nhanes.htm (accessed 2010 Jan. 10).

21. Bar-Oz B, Koren G, Nguyen P, et al. Folate fortification and supplementation - are we there yet? Reprod Toxicol 2008;25: 408-12.

22. Houghton LA, Sherwood KL, Pawlosky R, et al. [6S]-5-methyltetrahydrofolate is at least as effective as folic acid in preventing a decline in blood folate concentrations during lactation. Am J Clin Nutr 2006;83:842-50.

23. Wilson RD, Johnson JA, Wyatt P, et al. Preconceptional vita- 
min/folic acid supplementation 2007: the use of folic acid in combination with a multivitamin supplement for the prevention of neural tube defects and other congenital anomalies. $J$ Obstet Gynaecol Can 2007;29:1003-26.

24. Wald NJ, Law M, Hoffbrand AV. Folic acid fortification in the prevention of neural tube defects. Am J Clin Nutr 2004;80:1665-6.

25. Cole BF, Baron JA, Sandler RS, et al. Folic acid for the prevention of colorectal adenomas: a randomized clinical trial. JAMA 2007;297:2351-9.

26. Hirsch S, Sanchez H, Albala C, et al. Colon cancer in Chile before and after the start of the flour fortification program with folic acid. Eur J Gastroenterol Hepatol 2009;21:436-9.

27. Allen LH. How common is vitamin B-12 deficiency? Am J Clin Nutr 2009;89(supp):693S-6S.

28. Yajnik CS, Deshpande SS, Jackson AA, et al. Vitamin B12 and folate concentrations during pregnancy and insulin resistance in the offspring: the Pune maternal nutrition study. Diabetologia 2008;51:29-38.

29. Pfeiffer CM, Fazili Z, Zhang M. Folate analytical methodology. In: LB Bailey, editor. Folate in health in disease. 2nd ed. Boca Raton (FL): CRC Press, Taylor \& Francis Group; 2010.

30. Fazili Z, Pfeiffer CM, Zhang M, et al. Influence of 5,10-methylenetetrahydrofolate reductase polymorphism on whole-blood folate concentrations measured by LC-MS/MS, microbiologic assay, and bio-rad radioassay. Clin Chem 2008;54:197-201.

31. Kirkpatrick SI, Tarasuk V. Food insecurity is associated with nutrient inadequacies among Canadian adults and adolescents. $J$ Nutr 2008;138(3):604-12.
Affiliations: From the Children's Hospital of Eastern Ontario Research Institute (Colapinto, Tremblay), Institute of Population Health (Colapinto) and Department of Pediatrics (Tremblay), University of Ottawa, Ottawa, Ont.; and the Hospital for Sick Children and Department of Nutritional Sciences (O’Connor), University of Toronto, Toronto, Ont.

Contributors: All of the authors contributed to the conception and design of the study. Cynthia Colapinto conducted the analysis, and all of the authors assisted in the interpretation of the results. Cynthia Colapinto drafted the manuscript. All of the authors critically reviewed the manuscript for important intellectual content and approved the final version submitted for publication.

Funding: This research was supported by a CIHR Health Professionals Fellowship Award in the area of public health (funding reference no. 180375) and by a Statistics Canada Tom Symon's Fellowship Award to Cynthia Colapinto.

Acknowledgements: The authors thank the Health Analysis Division at Statistics Canada, in particular Tracey Bushnik and Michelle Rotermann for their support during the analysis stage of this research. The authors also thank Penny Jee for her review of the laboratory methods and Trevor Stewart for his review and feedback on the manuscript. 